\title{
Randomized controlled trial of piperacillin- tazobactam, cefepime and ertapenem for the treatment of urinary tract infection caused by extended-spectrum beta- lactamase-producing Escherichia coli
}

Yu Bin Seo', Jacob Lee ${ }^{1}$, Young Keun Kim², Seung Soon Lee³, Jeong-a Lee ${ }^{3}$, Hyo Youl Kim², Young Uh', Han-Sung Kim ${ }^{5}$ and Wonkeun Song ${ }^{6^{*}}$

\begin{abstract}
Background: Due to limited therapeutic options, the spread of extended-spectrum beta-lactamases (ESBLs) have become a major public health concern. We conducted a prospective, randomized, open-label comparison of the therapeutic efficacy of piperacillin-tazobactam (PTZ), cefepime, and ertapenem in febrile nosocomial urinary tract infection with ESBL-producing Escherichia coli (ESBL-EC).

Methods: This study was conducted at three university hospitals between January 2013 and August 2015. Hospitalized adult patients presenting with fever were screened for healthcare-associated urinary tract infection (HA-UTI). When ESBL-EC was solely detected and susceptible to a randomized antibiotic in vitro, the case was included in the final analysis. Participants were treated for 10-14 days with PTZ, cefepime, or ertapenem.

Results: A total of 66 participants were evenly assigned to the PTZ and ertapenem treatment groups. After the recruitment of six participants, assignment to the cefepime treatment group was stopped because of an unexpectedly high treatment failure rate. The baseline characteristics of these participants did not differ from participants in other treatment groups. The clinical and microbiological response to PTZ treatment was estimated to be $94 \%$ and was similar to the response to ertapenem treatment. The efficacy of cefepime was 33.3\%. In the cefepime group, age, Charlson comorbidity index, genotype, and minimal inhibitory concentration (MIC) did not significantly affect the success of treatment. Similarly, genotype seemed to be irrelevant with respect to clinical outcome in the PTZ group. Expired cases tended to involve septic shock with a high Charlson comorbidity index and high MIC.
\end{abstract}

Conclusion: Results from this study suggest that PTZ is effective in the treatment of urinary tract infection caused by ESBL-EC when the in vitro test indicates susceptibility. In addition, cefepime should not be used as an alternative treatment for urinary tract infection caused by ESBL-EC.

Trial registration: The trial was registered with the Clinical Research Information Service of Korea Centers for Disease Control and Prevention. (KCT0001895)

Keywords: Extended spectrum, Beta-lactamase, Piperacillin-tazobactam, Cefepime, Ertapenem

\footnotetext{
* Correspondence: swonkeun@hallym.or.kr

${ }^{6}$ Department of Laboratory Medicine, Kangnam Sacred Heart Hospital,

Hallym University College of Medicine, 1 Shingil-ro, Youngdeungpo-gu, Seoul

150-950, Korea

Full list of author information is available at the end of the article
} 


\section{Background}

The spread of extended-spectrum beta-lactamase (ESBL)producing organisms has gradually increased in hospitals and long-term care facilities [1]. ESBLs are enzymes that hydrolyze most beta-lactam antibiotics including penicillins, advanced-generation cephalosporins, and aztreonam. The genes of ESBLs are encoded on transferable plasmids, which can carry multiple co-resistance genes for other non-beta-lactam antibiotics [2,3]. The spread of ESBLs has become a major public health concern due to limited therapeutic options.

Compared to non-ESBL-producing organism infections, those with ESBL-producing organisms are related to poor clinical outcomes [4]. Carbapenems are generally considered the drug of choice for ESBL-producing organism infections due to their stability against ESBLs $[5,6]$. However, their use should be restricted considering the emergence of carbapenem-resistant organisms [7]. Alternative treatments are urgently needed to relieve the selective pressure for carbapenem [8,9]. Thus, over the past few decades, numerous studies have been conducted to determine possible alternatives.

Currently, the most frequently mentioned alternative treatments are beta-lactam/beta-lactamase inhibitors (BLBLI), cephamycins, cefepime, and aminoglycosides [10-20]. Results have been promising, but several studies have reported suboptimal outcomes of cefepime or piperacillin-tazobactam (PTZ) treatment [21-23]. Because previous studies were conducted with observational methods, these conflicting results could be due to confounding factors, such as mixed sources of infection, variability in dosing, and different patient characteristics. To overcome the limitations of observational studies, we conducted a prospective, randomized, open-label comparison of the therapeutic efficacy of PTZ, cefepime, and ertapenem in patients with febrile nosocomial urinary tract infection (UTI) with ESBL-producing Escherichia coli (EBSL-EC).

\section{Methods}

\section{Study setting}

This study was conducted at three university hospitals between January 2013 and August 2015. Hospitalized adult patients ( $\geq 19$ years of age) presenting with fever were screened for healthcare-associated UTI (HA-UTI), which was defined according to the CDC/NHSN surveillance recommendations [24]. Exclusion criteria were presence of suspicious or confirmatory infectious foci other than HA-UTI, any use of antibiotics within 7 days prior to recruitment for any reason, any complicating urinary factors that could not be effectively treated during the trial (such as obstruction, suspected or confirmed prostatitis, and epididymitis), indwelling urinary catheters expected to remain in place after completion of therapy, and need for renal replacement therapy. After providing written consent, participants were randomly assigned to receive treatment for 10-14 days with PTZ, cefepime, or ertapenem at each institute, in that order. Clinical data on age, gender, comorbidities, Charlson comorbidity index (CCI), and APACHE II score were collected. On day 5-7 of the initial therapy, the investigator at each institute performed a urine culture to determine whether continuation of the study therapy was appropriate. When ESBL-EC was solely detected and was susceptible to a randomized antibiotic regardless of the sensitivities to other antibiotics, the case was included in the final analysis. If a patient receiving a randomized antibiotic dropped out, that antibiotic was given to the next participant. Because randomization was performed at each institute, a laboratory center monitored the balance in sample sizes across the groups over time. This study was performed in accordance with the CONSORT (Consolidated Standards of Reporting Trials) statement.

\section{Antibiotic regimen}

All patients received doses adjusted according to renal function. For PTZ, patients with creatinine clearance (Ccr) $>40 \mathrm{~mL} / \mathrm{min}$ were treated with $4.5 \mathrm{~g}$ every $6 \mathrm{~h}$, those with $\mathrm{Ccr}$ of $20-40 \mathrm{~mL} / \mathrm{min}$ received 2.25 g every $6 \mathrm{~h}$, and those with $\mathrm{Ccr}<20 \mathrm{~mL} / \mathrm{min}$ received 8 g every $8 \mathrm{~h}$. For cefepime, patients with $\mathrm{Ccr}>60 \mathrm{~mL} / \mathrm{min}$ were treated with 2 g every $12 \mathrm{~h}$, those with Ccr of 30-60 mL/min received 2 g every $24 \mathrm{~h}$, and those with $\mathrm{Ccr}<30 \mathrm{~mL} / \mathrm{min}$ received $1 \mathrm{~g}$ every $24 \mathrm{~h}$. For ertapenem, patients with Ccr $>30 \mathrm{~mL} / \mathrm{min}$ were treated with $1 \mathrm{~g}$ every $24 \mathrm{~h}$, and those with $\mathrm{Ccr} \leq 30 \mathrm{~mL} / \mathrm{min}$ received $500 \mathrm{mg}$ daily.

\section{Bacterial isolates}

Urine and blood cultures were conducted in the microbiological laboratory at each hospital prior to antibiotic therapy. To evaluate the microbiological response, urine culture was repeated on day 10-14. At each hospital, microbiological identification was carried out using the Vitek 2 system (bioMérieux Vitek, Hazelwood, MO). Vitek GNI cards containing an ESBL test were used. Susceptibility to multiple antibiotics (including amikacin, ampicillin, ampicillin-sulbactam, aztreonam, cefepime, cefotaxime, cefotetan, ceftazidime, cephalothin, ciprofloxacin, ertapenem, gentamicin, imipenem, PTZ, and trimethoprim-sulfamethoxazole) was recorded. When an ESBL-EC was isolated, the sub-cultured specimen was delivered to Kangnam Sacred Heart Hospital for genotyping of ESBLs, AmpC beta-lactamases, and carbapenemases. For ESBLs-positive isolates, a PCR and sequencing strategy was used to characterize enzymes related to the ESBLs (TEM, SHV, CTX-M, and GES), AmpC beta-lactamases (DHA, MOX, and CMY), and carbapenemases (KPC, NDM, IMP, VIM, and OXA-48) using primers previously 
described [25-29]. CTX-M type sequencing primers used in this study are summarized in Table 1. Using two primer pairs, we amplified genes included in the CTX-M-1 (bla $a_{\text {СТХ-М-1 }}, b l a_{\text {СТХ-М-3}}$, and $\left.b l a_{\text {СТХ-М-15 }}\right)$ and CTX-M-9 groups $\left(b l a_{\mathrm{CTX}-\mathrm{M}-9}, b l a_{\mathrm{CTX}-\mathrm{M}-14}\right.$, and $\left.b l a_{\mathrm{CTX}-\mathrm{M}-27}\right)$. Then we sequenced the PCR products using identical primer pairs to identify each specific $b l a_{\text {CTX-M }}$ gene. The identified nucleotide sequences were compared with reference bla $a_{\text {CTX-M }}$ alleles (http://www.lahey.org/studies/). We performed species identification using the Vitek 2 system but did not identify the strain using multilocus sequence typing or pulsed field gel electrophoresis.

\section{Clinical and microbiological efficacy}

Clinical and microbiological responses were evaluated by the investigators on day $3-5,10-14$, and $28-30$. Clinical success was defined as resolution of fever and symptoms of UTI present at entry with no development of new symptoms. If clinical improvement was not achieved until day $3-5$, the case was defined as a clinical failure. Microbiological success was defined as elimination of ESBL-producing $E$. coli on a urine culture performed on day 10-14. Emergence of E. coli resistance to randomized antibiotic treatment, relapse rate, reinfection rate, and 28-day mortality were evaluated on day $28-30$.

\section{Statistical analysis}

One-way analysis of variance (ANOVA) with post-hoc Bonferroni analysis was used to compare continuous variables among the three groups. Chi-square and Fisher's exact tests were used for bivariate analyses. To identify risk factors for treatment failure, multivariate analysis is generally used. However, there were too few failure cases to conduct this analysis. Therefore, a descriptive approach was used in the genotype and MIC analyses. All $p$-values were two sided and accepted when $p<0.05$. Statistical analysis was performed using SPSS 18.0 software (SPSS Korea, Seoul, Korea).

\section{Results}

\section{Study subjects}

During the study period, a total of 72 participants were enrolled. Of these, 66 participants were evenly assigned to the PTZ and ertapenem treatment groups. After recruitment of six participants to the cefepime treatment group, allocation to this treatment group was stopped due to an unexpectedly high treatment failure rate.
Table 2 shows the baseline characteristics of the participants. The average age of participants (65 years) did not vary among the three groups. There were more female than male participants assigned to both the PTZ (female 90.9\%) and ertapenem (female $78.8 \%$ ) treatment groups, but significant gender differences were not observed between the two groups $(p=0.303)$. In the cefepime group, there was an equal distribution of female and male participants, and the gender ratio was significantly different from the two other groups $(p=0.049)$. With respect to comorbidities, the Charlson comorbidity index was similar among the three groups. Almost $65 \%$ of the participants had at least one or more underlying disease. Septic shock and concomitant bacteremia were presented in $20-30 \%$ of participants in the PTZ and ertapenem groups and did not show statistical differences. APACHE II scores were similar among the three groups. Septic shock and bacteremia were not detected in the cefepime group.

\section{Clinical and microbiological outcomes}

Clinical and microbiological outcomes are summarized in Table 3. Clinical success rate was $93.9 \%$ (31/33) with PTZ and $97.0 \%(32 / 33)$ with ertapenem; the rates were not statistically different $(p=0.500)$. However, the clinical success rate with cefepime was $33.3 \%(2 / 6)$, which was significantly lower than those of the other antibiotic groups $(p<0.001)$. The microbiological success rates of PTZ and ertapenem were the same at 97.0\% (32/33), while the cefepime group achieved a $33.3 \%$ success rate (2/6). The 28-day mortality was also the same between the PTZ and ertapenem groups with a rate of $6.1 \%(2 / 33)$ in both groups. On the other hand, the rate was 33.3\% $(2 / 6)$ in the cefepime group $(p=0.108)$. There were no cases of emergence of $E$. coli resistance to randomized antibiotics, relapse, or reinfection. In the case of microbiological failure, the MICs of late cultures at 10-14 days were not different from early cultures. All patients with a positive culture at test of cure had clinical symptoms that were consistent with UTI.

\section{Genotypic analysis in the cefepime and piperacillin- tazobactam groups}

There were no ESBL-EC isolates combined with AmpC or carbapenemase enzymes in this study. In the cefepime group, only two participants achieved clinically successful recovery (Table 4). There were four failure cases and

Table 1 Primers used for PCR amplification and sequencing of bla $a_{C T X-M}$ genes

\begin{tabular}{lllll}
\hline Target & Name of primer & Sequence $\left(5^{\prime} \boldsymbol{\rightarrow}\right.$ 3') $\left.^{\prime}\right)$ & Expected size of amplicon (bp) & Reference \\
\hline CTX-M-1 group & CTX-M-1F & GCAGCACCAGTAAAGTGATGGGCTGGGTGAAGTAAGTGACC & 591 & [28] \\
& CTX-M-1R & & & \\
CTX-M-9 group & CTX-M-9F & GCTGGAGAAAAGCAGCGGAGGTAAGCTGACGCAACGTCTG & 474 & [29] \\
& CTX-M-9R & & & \\
\hline
\end{tabular}


Table 2 Demographic characteristics of study subjects

\begin{tabular}{|c|c|c|c|c|}
\hline & $\begin{array}{l}\text { Piperacillin/tazobactam } \\
(N=33)\end{array}$ & $\begin{array}{l}\text { Cefepime } \\
(N=6)\end{array}$ & $\begin{array}{l}\text { Ertapenem } \\
(N=33)\end{array}$ & $p$-value \\
\hline Age & $68.8 \pm 14.4$ & $75.3 \pm 6.6$ & $65.2 \pm 16.9$ & 0.281 \\
\hline Female & $30(90.9)$ & $3(50.0)$ & $26(78.8)$ & 0.049 \\
\hline \multicolumn{5}{|l|}{ Comorbidity, n (\%) } \\
\hline Ischemic heart disease & $0(0)$ & $0(0)$ & $1(3.0)$ & 1.000 \\
\hline Diabetes mellitus & $12(36.4)$ & $1(16.7)$ & $15(45.5)$ & 0.474 \\
\hline Cerebrovascular accident & $5(15.2)$ & $1(16.7)$ & $2(6.1)$ & 0.420 \\
\hline Dementia & $3(9.1)$ & $0(0)$ & $2(6.1)$ & 1.000 \\
\hline Hemiplegia & $2(6.1)$ & $0(0)$ & $2(6.1)$ & 1.000 \\
\hline Congestive heart failure & $5(15.2)$ & $1(16.7)$ & $1(3.0)$ & 0.230 \\
\hline COPD & $1(3.0)$ & $0(0)$ & $1(3.0)$ & 1.000 \\
\hline Chronic kidney disease & $2(6.1)$ & $0(0)$ & $2(6.1)$ & 1.000 \\
\hline Liver cirrhosis & $2(6.1)$ & $0(0)$ & $4(12.1)$ & 0.809 \\
\hline Solid tumor & $6(18.2)$ & $1(16.7)$ & $7(21.2)$ & 1.000 \\
\hline Lymphoma & $1(3.0)$ & $0(0)$ & $2(6.1)$ & 1.000 \\
\hline None & $12(36.4)$ & $2(33.3)$ & $12(36.4)$ & 1.000 \\
\hline Charlson comorbidity index & $4.7 \pm 3.0$ & $4.7 \pm 1.0$ & $4.5 \pm 3.0$ & 0.951 \\
\hline Bacteremia, n (\%) & $9(27.3)$ & $0(0)$ & $7(21.2)$ & 0.477 \\
\hline Septic shock, n (\%) & $9(24.2)$ & $2(33.3)$ & $11(33.3)$ & 0.928 \\
\hline APACH II score & $12.9 \pm 2.9$ & $16.5 \pm 6.4$ & $16.6 \pm 5.6$ & 0.298 \\
\hline
\end{tabular}

two deaths. While the MIC of cefepime was $1 \mu \mathrm{g} / \mathrm{mL}$ or $2 \mu \mathrm{g} / \mathrm{mL}$, the successful cases all had an MIC of $2 \mu \mathrm{g} / \mathrm{mL}$. The genotype was predominantly CTX-M-9, but one case was detected as SHV-2. The genotype did not appear to significantly affect the success of treatment. In addition, age and Charlson comorbidity index did not seem to be directly related to clinical success. All mortality cases occurred under conditions of septic shock.

In the PTZ group, treatment was successful except in two cases (Table 4). In most cases, the MIC was $16 \mu \mathrm{g} / \mathrm{mL}$ and accounted for $72.7 \%$ of the total. Although the clinical outcome was satisfactory in most cases of $16 \mu \mathrm{g} / \mathrm{mL} \mathrm{MIC \text {, }}$ all failure and mortality cases were in the $16 \mu \mathrm{g} / \mathrm{mL}$ MIC group. Ten samples were lost during transport or over the course of the experiment. CTX-M-14, CTX-M-15, and CTX-M-27 were frequently observed. The genotypes of the mortality cases were CTX-M-15 or CTX-M-27. Similar to cefepime, the genotype seemed to be irrelevant with respect to clinical outcome. Deaths tended to be associated with septic shock with high Charlson comorbidity index and high MIC.

\section{Discussion}

This is the first randomized study comparing the efficacy of PTZ, cefepime, and ertapenem. Although the sample size was small, results from the study showed that PTZ was as effective as ertapenem for the treatment of ESBL-EC UTI. Clinical and microbiological response to PTZ treatment was estimated to be $94 \%$. Unexpectedly, the efficacy of cefepime was only $33.3 \%$, suggesting that cefepime is not an appropriate therapeutic alternative for ESBL-EC UTI.

ESBLs might be inhibited by beta-lactamase inhibitors; thus, it is theoretically attractive to use BLBLI combinations to treat ESBL infections. In fact, a large, multicenter, prospective observational study has reported that outcomes using BLBLIs were comparable to those with carbapenem in the treatment of ESBL-EC blood stream

Table 3 Clinical and microbiological outcomes according to the antibiotic groups

\begin{tabular}{|c|c|c|c|c|}
\hline & $\begin{array}{l}\text { Piperacillin/tazobactam } \\
(N=33)\end{array}$ & $\begin{array}{l}\text { Cefepime } \\
(N=6)\end{array}$ & $\begin{array}{l}\text { Ertapenem } \\
(N=33)\end{array}$ & $p$-value \\
\hline Clinical success, n (\%) & $31(93.9)$ & $2(33.3)$ & $32(97.0)$ & $<0.001$ \\
\hline Microbiological success, n (\%) & $32(97.0)$ & $2(33.3)$ & $32(97.0)$ & $<0.001$ \\
\hline Clinical and microbiological success, n (\%) & $31(93.9)$ & $2(33.3)$ & $32(97.0)$ & $<0.001$ \\
\hline 28-days mortality, n (\%) & $2(6.1)$ & $2(33.3)$ & $2(6.1)$ & 0.108 \\
\hline
\end{tabular}


Table 4 Schematic description of clinical outcomes according to MIC, genotype, age, Charlson comorbidity index (CCI), presence of concomitant bacteremia and septic shock in cefepime, piperacillin/tazobactam and ertapenem groups

\begin{tabular}{|c|c|c|c|c|c|c|}
\hline Case & $\mathrm{MIC}(\mu \mathrm{g} / \mathrm{mL})$ & ESBLs genotype & $\mathrm{CCl}$ & Bacteremia & Septic shock & Clinical outcome \\
\hline \multicolumn{7}{|c|}{ A. Cefepime $(N=6)$} \\
\hline Patient 1 & 2 & CTX-M-14 & 5 & No & No & Success \\
\hline Patient 2 & 2 & CTX-M-14 & 3 & No & No & Success \\
\hline Patient 3 & 1 & CTX-M-14 & 4 & No & No & Failure \\
\hline Patient 4 & 2 & CTX-M-14 & 6 & No & No & Failure \\
\hline Patient 5 & 1 & SHV-12 & 5 & No & Yes & Failure and expired \\
\hline Patient 6 & 2 & CTX-M-14 & 5 & No & Yes & Failure and expired \\
\hline \multicolumn{7}{|c|}{ B. Piperacillin/tazobactam $(N=33)$} \\
\hline Patient 1 & 4 & CTX-M-14 & 6 & No & No & Success \\
\hline Patient 2 & 4 & CTX-M-15 & 5 & No & Yes & Success \\
\hline Patient 3 & 4 & CTX-M-15 & 0 & No & No & Success \\
\hline Patient 4 & 4 & CTX-M-15 & 1 & No & No & Success \\
\hline Patient 5 & 4 & CTX-M-27 & 9 & No & No & Success \\
\hline Patient 6 & 4 & CTX-M-27 & 9 & No & No & Success \\
\hline Patient 7 & 4 & CTX-M-27 & 9 & No & No & Success \\
\hline Patient 8 & 8 & CTX-M-14 & 3 & Yes & Yes & Success \\
\hline Patient 9 & 8 & CTX-M-14 & 1 & No & No & Success \\
\hline Patient 10 & 16 & CTX-M-1 & 4 & No & No & Success \\
\hline Patient 11 & 16 & CTX-M-3 & 2 & No & Yes & Success \\
\hline Patient 12 & 16 & CTX-M-14 & 3 & No & No & Success \\
\hline Patient 13 & 16 & CTX-M-14 & 3 & Yes & Yes & Success \\
\hline Patient 14 & 16 & CTX-M-15 & 1 & No & Yes & Success \\
\hline Patient 15 & 16 & CTX-M-15 & 4 & No & No & Success \\
\hline Patient 16 & 16 & CTX-M-27 & 0 & No & No & Success \\
\hline Patient 17 & 16 & CTX-M-15 & 3 & No & No & Success \\
\hline Patient 18 & 16 & CTX-M-14 & 5 & No & No & Success \\
\hline Patient 19 & 16 & CTX-M-14 & 7 & No & No & Success \\
\hline Patient 20 & 16 & CTX-M-14 & 1 & Yes & No & Success \\
\hline Patient 21 & 16 & CTX-M-14 & 8 & No & No & Success \\
\hline Patient 22 & 16 & Not tested & 5 & No & No & Success \\
\hline Patient 23 & 16 & Not tested & 2 & No & Yes & Success \\
\hline Patient 24 & 16 & Not tested & 7 & No & No & Success \\
\hline Patient 25 & 16 & Not tested & 3 & No & No & Success \\
\hline Patient 26 & 16 & Not tested & 7 & No & No & Success \\
\hline Patient 27 & 16 & Not tested & 8 & No & No & Success \\
\hline Patient 28 & 16 & Not tested & 5 & No & No & Success \\
\hline Patient 29 & 16 & Not tested & 5 & No & No & Success \\
\hline Patient 30 & 16 & Not tested & 3 & Yes & No & Success \\
\hline Patient 31 & 16 & Not tested & 7 & Yes & Yes & Success \\
\hline Patient 32 & 16 & CTX-M-15 & 9 & Yes & Yes & Failure and expired \\
\hline Patient 33 & 16 & CTX-M-27 & 10 & No & Yes & Failure and expired \\
\hline
\end{tabular}


Table 4 Schematic description of clinical outcomes according to MIC, genotype, age, Charlson comorbidity index (CCI), presence of concomitant bacteremia and septic shock in cefepime, piperacillin/tazobactam and ertapenem groups (Continued)

\begin{tabular}{|c|c|c|c|c|c|c|}
\hline \multicolumn{7}{|c|}{ C. Ertapenem $(N=33)$} \\
\hline Patient 1 & 0.5 & CTX-M-15 & 0 & No & No & Success \\
\hline Patient 2 & 0.5 & CTX-M-27 & 0 & No & No & Success \\
\hline Patient 3 & 0.5 & CTX-M-14 & 1 & No & No & Success \\
\hline Patient 4 & 0.5 & CTX-M-15 & 1 & No & No & Success \\
\hline Patient 5 & 0.5 & CTX-M-14 & 1 & Yes & No & Success \\
\hline Patient 6 & 0.5 & CTX-M-15 & 1 & No & Yes & Success \\
\hline Patient 7 & 0.5 & CTX-M-3 & 2 & No & Yes & Success \\
\hline Patient 8 & 0.5 & CTX-M-14 & 2 & Yes & Yes & Success \\
\hline Patient 9 & 0.5 & CTX-M-14 & 3 & No & No & Success \\
\hline Patient 10 & 0.5 & CTX-M-15 & 3 & No & No & Success \\
\hline Patient 11 & 0.5 & CTX-M-15 & 3 & No & No & Success \\
\hline Patient 12 & 0.5 & CTX-M-14 & 3 & Yes & No & Success \\
\hline Patient 13 & 0.5 & CTX-M-14 & 3 & Yes & Yes & Success \\
\hline Patient 14 & 0.5 & CTX-M-14 & 3 & Yes & Yes & Success \\
\hline Patient 15 & 0.5 & CTX-M-1 & 4 & No & No & Success \\
\hline Patient 16 & 0.5 & CTX-M-15 & 4 & No & No & Success \\
\hline Patient 17 & 0.5 & CTX-M-14 & 5 & No & No & Success \\
\hline Patient 18 & 0.5 & CTX-M-14 & 5 & No & No & Success \\
\hline Patient 19 & 0.5 & CTX-M-15 & 5 & No & No & Success \\
\hline Patient 20 & 0.5 & CTX-M-14 & 5 & Yes & No & Success \\
\hline Patient 23 & 0.5 & CTX-M-15 & 5 & No & Yes & Success \\
\hline Patient 21 & 0.5 & CTX-M-14 & 6 & Yes & No & Success \\
\hline Patient 22 & 0.5 & CTX-M-14 & 7 & No & No & Success \\
\hline Patient 24 & 0.5 & CTX-M-14 & 7 & No & No & Success \\
\hline Patient 25 & 0.5 & CTX-M-14 & 7 & No & No & Success \\
\hline Patient 26 & 0.5 & CTX-M-14 & 8 & No & No & Success \\
\hline Patient 27 & 0.5 & CTX-M-14 & 8 & No & No & Success \\
\hline Patient 28 & 0.5 & CTX-M-27 & 9 & No & No & Success \\
\hline Patient 29 & 0.5 & CTX-M-27 & 9 & No & No & Success \\
\hline Patient 30 & 0.5 & CTX-M-27 & 9 & No & No & Success \\
\hline Patient 31 & 0.5 & CTX-M-27 & 10 & No & No & Success \\
\hline Patient 32 & 0.5 & CTX-M-14 & 9 & Yes & Yes & Failure and expired \\
\hline Patient 33 & 0.5 & CTX-M-15 & 7 & Yes & Yes & Failure and expired \\
\hline
\end{tabular}

Not tested: The isolate was ESBLs-positive by Vitek-2 system but not tested the ESBLs genotyping due to loss of the isolate

infection [10]. In addition, a recent meta-analysis found no statistical differences in mortality between carbapenem treatment and BLBLI treatment in patients with bacteremia caused by ESBL-producing pathogens [30]. However, in another study, BLBLI appeared to be inferior to carbapenem for treatment of bacteremia [31]. These inconclusive results might be due to differences in the proportion of bacteremia sources among the various studies since the infection site can significantly influence the therapeutic efficacy of antibiotics. To overcome issues due to infection heterogeneity, this study focused on the treatment of UTIs.

According to our results, PTZ is a reliable alternative in the treatment of ESBL-EC-proven UTI. An inoculum effect has been proposed as a major limitation of PTZ [32]. PTZ has some merits for use in cases of UTI. Tazobactam is mainly excreted in the urine, and its high concentration in the urine is noted in the presence of piperacillin [33]. In addition, UTIs can have a relatively lower bacterial burden than other infectious diseases, 
such as pneumonia, complicated intra-abdominal infection, and blood stream infection. Therefore, PTZ might be able to overcome the inoculum effect in UTIs. Interestingly, mortality cases were found in participants with a high MIC who received PTZ treatment. Due to the small sample size, it was difficult to determine whether a higher MIC of PTZ is an important risk factor for treatment failure. However, in this study, multiple cases with a $16 \mu \mathrm{g} / \mathrm{mL}$ MIC of PTZ were successfully treated. As discussed in a previous study, the MIC might not be a significant risk factor in UTIs [16]. Treatment failure seems to be closely related to the patient's baseline conditions, irrespective of the MIC.

Cefepime is frequently used for treatment of healthcare associated infections and shows greater stability in vitro against ESBL-producing pathogens than other cephalosporins [34]. Some clinical studies have reported successful treatment using cefepime in cases of ESBLproducing bacterial infection $[19,35]$. However, several other studies have shown disappointing outcomes when using cefepime to treat bacteremic conditions [20,23]. Cefepime is highly vulnerable to the inoculum effect, and a high MIC is an important risk factor for treatment failure [32]. As seen in our study, cefepime was not effective in the treatment of UTIs even in non-bacteremic conditions. Treatment failure was also observed despite an MIC of $1 \mu \mathrm{g} / \mathrm{mL}$ or $2 \mu \mathrm{g} / \mathrm{mL}$. Thus, a lower MIC does not predict clinical success in cefepime treatment. Although cefepime is excreted mostly unchanged in urine, it can be easily inactivated by ESBLs in UTIs. Otherwise, the results we observed might be due to the emergence of phenotypic heterogeneous resistance to cefepime during treatment [36]. Another cause of treatment failure could be under-dosing of cefepime. In Korea, cefepime has been approved to be administered at $1 \mathrm{~g}$ twice a day for mild or moderate infection, $2 \mathrm{~g}$ twice a day for severe infection, and $2 \mathrm{~g}$ three times a day for neutropenic patients if renal function is normal. The recommended dose is the same in most other countries. However, some studies recommended higher doses of cefepime than usual for clinical doses. One study reported that doses of at least $2 \mathrm{~g}$ every $8 \mathrm{~h}$ are required to treat infections considering clinical pharmacodynamics [37]. However, that study enrolled patients with non-urinary tract infections, and the pathogen of focus was Pseudomonas aeruginosa. Therefore, it is difficult to infer the same conclusion from this study. Other studies using a series of 5000-subject Monte Carlo simulations mentioned that a cefepime dose of $2 \mathrm{~g}$ every $6 \mathrm{~h}$ provided favorable probability [38]. Considering results from existing studies, further clinical studies increasing the dose of cefepime seem to be necessary to clarify the failure of cefepime.

This study has several limitations. First, the statistical power was low due to the small number of participants.
To estimate the sample size for clinical research studies, the variance or standard deviation is obtained from previous studies. When there are no previous studies, a formal sample size calculation might not be appropriate. We decided to complete the study according to the study period regardless of the sample size, as in the pilot study. During the study period, the number of patients susceptible in vitro to PTZ was unexpectedly small. Furthermore, the exclusion criteria were strict in order to reduce possible confounding factors. Accordingly, the sample size was only 33 participants in each group except the cefepime group; however, this is a common pilot sample study size for a two-arm trial [39]. In order to have more confidence in the outcome, a larger sample size is needed in future studies. Second, it has been suggested that ESBL-Klebsiella pneumoniae is associated with higher mortality than ESBL-EC bacteremia [40]. Therefore, the results could not be generalized to pathogens other than E. coli. Third, the genotype was not determined in some cases due to loss of the isolate. Fourth, the molecular PCR typing was not done for cefepime resistance gene such as OXA-30. Results could be interpreted differently in situations with other ESBL genotypes. In the Republic of Korea, the predominant types of ESBLs in $E$. coli are CTX-M-14 and CTX-M-15, which is consistent with the results of the tested isolates in our study [41]. In our study, the tested isolates demonstrated similar predominance. Therefore, these results could be applied to the situation of high spread of the CTX-M type.

\section{Conclusion}

Alternatives for the treatment of ESBL-producing bacteria are urgently needed to suppress the emergence of carbapenem-resistant pathogens. Results from this study suggest that PTZ is effective in the treatment of UTI caused by ESBL-EC when the in vitro test indicates susceptibility. Empirical PTZ therapy for healthcareassociated UTI seems to be reasonable if the hospital epidemiological antimicrobial pattern of ESBLs (especially the CTX-M type) is dominantly in vitro susceptible to PTZ. In addition, cefepime should not be used as an alternative treatment in urinary tract infections caused by ESBL-EC.

\section{Abbreviations \\ ESBL-EC: ESBL-producing Escherichia coli; ESBLs: Extended-spectrum beta-lactamases; HA-UTI: Healthcare-associated urinary tract infection; MIC: Minimal inhibitory concentration; PTZ: Piperacillin-tazobactam; UTI: Urinary tract infection}

\section{Funding}

This study was supported by a research grant from the Korean Health Technology R\&D Project, Ministry of Health \& Welfare, Republic of Korea (HI12C0756).

Availability of data and materials

The data in this study can be accessed by sending a request to the corresponding author. 


\section{Authors' contributions}

YBS, JL: contribution to the study concept and design, analysis of the data, and writing the manuscript. YKK, SSL, JL, HYK, YU, H-SK: contribution to the collection and analysis of data. WS: contribution to the study concept and design and review of the manuscript. All authors gave final approval of the version to be published.

\section{Competing interests}

The authors declare that they have no competing interests.

\section{Consent for publication}

Not applicable.

\section{Publisher's Note}

Springer Nature remains neutral with regard to jurisdictional claims in published maps and institutional affiliations.

\section{Ethics approval and consent to participate}

This study was approved by the Institutional Review Board of Kangnam Sacred Heart Hospital (IRB no. 2012-12-119) and the Clinical Research Information Service of Korea Centers for Disease Control and Prevention (KCT0001895). Prior to enrollment, the clinical issues and suggested treatment were explained to each participant. Written consent was also obtained prior to enrollment. Participants were informed that they could withdraw at any time.

\section{Author details}

${ }^{1}$ Division of Infectious Diseases, Department of Internal Medicine, Kangnam Sacred Heart Hospital, Hallym University College of Medicine, Seoul, Republic of Korea. ${ }^{2}$ Department of Internal Medicine, Yonsei University Wonju College of Medicine, Wonju, Republic of Korea. ${ }^{3}$ Division of Infectious Diseases, Department of Internal Medicine, Hallym University Sacred Heart Hospital, Hallym University College of Medicine, Seoul, Republic of Korea. ${ }^{4}$ Department of Laboratory Medicine, Yonsei University Wonju College of Medicine, Wonju, Republic of Korea. ${ }^{5}$ Department of Laboratory Medicine, Hallym University Sacred Heart Hospital, Hallym University College of Medicine, Seoul, Republic of Korea. ${ }^{6}$ Department of Laboratory Medicine, Kangnam Sacred Heart Hospital, Hallym University College of Medicine, 1 Shingil-ro,

Youngdeungpo-gu, Seoul 150-950, Korea.

Received: 8 May 2016 Accepted: 30 May 2017

Published online: 07 June 2017

\section{References}

1. Thaden JT, Fowler VG, Sexton DJ, Anderson DJ. Increasing incidence of extended-Spectrum beta-Lactamase-producing Escherichia coli in community hospitals throughout the southeastern United States. Infect Control Hosp Epidemiol. 2016;37(1):49-54.

2. Schwaber MJ, Navon-Venezia S, Schwartz D, Carmeli Y. High levels of antimicrobial coresistance among extended-spectrum-beta-lactamase-producing Enterobacteriaceae. Antimicrob Agents Chemother. 2005;49(5):2137-9.

3. Morosini Ml, Garcia-Castillo M, Coque TM, Valverde A, Novais A, Loza E, et al. Antibiotic coresistance in extended-spectrum-beta-lactamase-producing Enterobacteriaceae and in vitro activity of tigecycline. Antimicrob Agents Chemother. 2006;50(8):2695-9.

4. Ramphal R, Ambrose PG. Extended-spectrum beta-lactamases and clinical outcomes: current data. Clin Infect Dis. 2006;42(Suppl 4):S164-72.

5. Paterson DL, Bonomo RA. Extended-spectrum beta-lactamases: a clinical update. Clin Microbiol Rev. 2005;18(4):657-86.

6. Rodriguez-Bano J, Pascual A. Clinical significance of extended-spectrum beta-lactamases. Expert Rev Anti-Infect Ther. 2008;6(5):671-83.

7. Nordmann P, Naas T, Poirel L. Global spread of Carbapenemase-producing Enterobacteriaceae. Emerg Infect Dis. 2011;17(10):1791-8.

8. Go ES, Urban C, Burns J, Kreiswirth B, Eisner W, Mariano N, et al. Clinical and molecular epidemiology of acinetobacter infections sensitive only to polymyxin B and sulbactam. Lancet. 1994;344(8933):1329-32.

9. Guh AY, Limbago BM, Kallen AJ. Epidemiology and prevention of carbapenem-resistant Enterobacteriaceae in the United States. Expert Rev Anti-Infect Ther. 2014;12(5):565-80.

10. Rodriguez-Bano J, Navarro MD, Retamar P, Picon E, Pascual A, ExtendedSpectrum Beta-Lactamases-Red Espanola de Investigacion en Patologia Infecciosa/Grupo de Estudio de Infeccion Hospitalaria G. Beta-Lactam/beta- lactam inhibitor combinations for the treatment of bacteremia due to extended-spectrum beta-lactamase-producing Escherichia coli: a post hoc analysis of prospective cohorts. Clin Infect Dis. 2012;54(2):167-74.

11. Lee CH, Su LH, Tang YF, Liu JW. Treatment of ESBL-producing Klebsiella pneumoniae bacteraemia with carbapenems or flomoxef: a retrospective study and laboratory analysis of the isolates. J Antimicrob Chemother. 2006;58(5):1074-7.

12. Han SB, Lee SC, Lee SY, Jeong DC, Kang JH. Aminoglycoside therapy for childhood urinary tract infection due to extended-spectrum betalactamase-producing Escherichia coli or Klebsiella pneumoniae. BMC Infect Dis. 2015;15:414.

13. Matsumura Y, Yamamoto M, Nagao M, Komori T, Fujita N, Hayashi A, et al. Multicenter retrospective study of cefmetazole and flomoxef for treatment of extended-spectrum-beta-lactamase-producing Escherichia coli bacteremia. Antimicrob Agents Chemother. 2015;59(9):5107-13.

14. Tasbakan Ml, Pullukcu H, Sipahi OR, Yamazhan T, Ulusoy S. Nitrofurantoin in the treatment of extended-spectrum beta-lactamase-producing Escherichia colirelated lower urinary tract infection. Int J Antimicrob Agents. 2012;40(6):554-6.

15. Gavin PJ, Suseno MT, Thomson RB Jr, Gaydos JM, Pierson CL, Halstead DC, et al. Clinical correlation of the CLSI susceptibility breakpoint for piperacillintazobactam against extended-spectrum-beta-lactamase-producing Escherichia coli and Klebsiella species. Antimicrob Agents Chemother. 2006;50(6):2244-7.

16. Retamar P, Lopez-Cerero L, Muniain MA, Pascual A, Rodriguez-Bano J, Group E-RG. Impact of the MIC of piperacillin-tazobactam on the outcome of patients with bacteremia due to extended-spectrum-beta-lactamaseproducing Escherichia coli. Antimicrob Agents Chemother. 2013;57(7):3402-4.

17. Doi A, Shimada T, Harada S, Iwata K, Kamiya T. The efficacy of cefmetazole against pyelonephritis caused by extended-spectrum beta-lactamaseproducing Enterobacteriaceae. Int J Infect Dis. 2013;17(3):e159-63.

18. Ipekci T, Seyman D, Berk H, Celik O. Clinical and bacteriological efficacy of amikacin in the treatment of lower urinary tract infection caused by extended-spectrum beta-lactamase-producing Escherichia coli or Klebsiella pneumoniae. J Infect Chemother. 2014;20(12):762-7.

19. Labombardi VJ, Rojtman A, Tran K. Use of cefepime for the treatment of infections caused by extended spectrum beta-lactamase-producing Klebsiella pneumoniae and Escherichia coli. Diagn Microbiol Infect Dis. 2006:56(3):313-5.

20. Lee NY, Lee CC, Huang WH, Tsui KC, Hsueh PR, Ko WC. Cefepime therapy for monomicrobial bacteremia caused by cefepime-susceptible extendedspectrum beta-lactamase-producing Enterobacteriaceae: MIC matters. Clin Infect Dis. 2013;56(4):488-95.

21. Ofer-Friedman H, Shefler C, Sharma S, Tirosh A, Tal-Jasper R, Kandipalli D, et al. Carbapenems versus Piperacillin-Tazobactam for bloodstream infections of Nonurinary source caused by extended-Spectrum Beta-Lactamase-producing Enterobacteriaceae. Infect Control Hosp Epidemiol. 2015;36(8):981-5.

22. Lee NY, Lee CC, Li CW, Li MC, Chen PL, Chang CM, et al. Cefepime therapy for Monomicrobial Enterobacter cloacae Bacteremia: unfavorable outcomes in patients infected by Cefepime-susceptible dose-dependent isolates. Antimicrob Agents Chemother. 2015;59(12):7558-63.

23. Chopra T, Marchaim D, Veltman J, Johnson P, Zhao JJ, Tansek R, et al. Impact of cefepime therapy on mortality among patients with bloodstream infections caused by extended-spectrum-beta-lactamase-producing Klebsiella pneumoniae and Escherichia coli. Antimicrob Agents Chemother. 2012;56(7):3936-42.

24. Horan TC, Andrus M, Dudeck MA. CDC/NHSN surveillance definition of health care-associated infection and criteria for specific types of infections in the acute care setting. Am J Infect Control. 2008;36(5):309-32.

25. Ryoo NH, Kim EC, Hong SG, Park YJ, Lee K, Bae IK, et al. Dissemination of SHV-12 and CTX-M-type extended-spectrum beta-lactamases among clinical isolates of Escherichia coli and Klebsiella pneumoniae and emergence of GES-3 in Korea. J Antimicrob Chemother. 2005;56(4):698-702.

26. Perez-Perez FJ, Hanson ND. Detection of plasmid-mediated AmpC betalactamase genes in clinical isolates by using multiplex PCR. J Clin Microbiol. 2002;40(6):2153-62.

27. Poirel L, Walsh TR, Cuvillier V, Nordmann P. Multiplex PCR for detection of acquired carbapenemase genes. Diagn Microbiol Infect Dis. 2011;70(1):119-23.

28. Abdalhamid B, Pitout JD, Moland ES, Hanson ND. Community-onset disease caused by Citrobacter freundii producing a novel CTX-M beta-lactamase, CTX-M-30, in Canada. Antimicrob Agents Chemother. 2004:48(11):4435-7.

29. Pitout JD, Hossain A, Hanson ND. Phenotypic and molecular detection of CTX-M-beta-lactamases produced by Escherichia coli and Klebsiella spp. J Clin Microbiol. 2004;42(12):5715-21. 
30. Vardakas KZ, Tansarli GS, Rafailidis PI, Falagas ME. Carbapenems versus alternative antibiotics for the treatment of bacteraemia due to Enterobacteriaceae producing extended-spectrum beta-lactamases: a systematic review and meta-analysis. J Antimicrob Chemother. 2012;67(12):2793-803.

31. Tamma PD, Han JH, Rock C, Harris AD, Lautenbach E, Hsu AJ, Avdic E, Cosgrove SE, Antibacterial Resistance Leadership G. Carbapenem therapy is associated with improved survival compared with piperacillin-tazobactam for patients with extended-spectrum beta-lactamase bacteremia. Clin Infect Dis. 2015;60(9):1319-25.

32. Thomson KS, Moland ES. Cefepime, piperacillin-tazobactam, and the inoculum effect in tests with extended-spectrum beta-lactamase-producing Enterobacteriaceae. Antimicrob Agents Chemother. 2001;45(12):3548-54

33. Komuro M, Maeda T, Kakuo H, Matsushita H, Shimada J. Inhibition of the renal excretion of tazobactam by piperacillin. J Antimicrob Chemother. 1994:34(4):555-64.

34. Sanders CC. In vitro activity of fourth generation cephalosporins against enterobacteriaceae producing extended-spectrum beta-lactamases. J Chemother. 1996;8(Suppl 2):57-62.

35. Goethaert K, Van Looveren M, Lammens C, Jansens H, Baraniak A, Gniadkowski M, et al. High-dose cefepime as an alternative treatment for infections caused by TEM-24 ESBL-producing Enterobacter aerogenes in severely-ill patients. Clin Microbiol Infect. 2006;12(1):56-62.

36. Ma W, Sun J, Yang S, Zhang L. Epidemiological and clinical features for cefepime heteroresistant Escherichia coli infections in Southwest China. Eur J Clin Microbiol Infect Dis. 2016;35(4):571-8.

37. Crandon JL, Bulik CC, Kuti JL, Nicolau DP. Clinical pharmacodynamics of cefepime in patients infected with Pseudomonas Aeruginosa. Antimicrob Agents Chemother. 2010;54(3):1111-6.

38. Zasowski E, Bland CM, Tam VH, Lodise TP. Identification of optimal renal dosage adjustments for high-dose extended-infusion cefepime dosing regimens in hospitalized patients. J Antimicrob Chemother. 2015;70(3):877-81.

39. Billingham SA, Whitehead AL, Julious SA. An audit of sample sizes for pilot and feasibility trials being undertaken in the United Kingdom registered in the United Kingdom clinical research network database. BMC Med Res Methodol. 2013;13:104

40. Apisarnthanarak A, Kiratisin P, Mundy LM. Predictors of mortality from community-onset bloodstream infections due to extended-spectrum beta-lactamase-producing Escherichia coli and Klebsiella pneumoniae. Infect Control Hosp Epidemiol. 2008:29(7):671-4.

41. Song W, Lee H, Lee K, Jeong SH, Bae IK, Kim JS, et al. CTX-M-14 and CTX-M-15 enzymes are the dominant type of extended-spectrum beta-lactamase in clinical isolates of Escherichia coli from Korea. J Med Microbiol. 2009;58(Pt 2):261-6.

\section{Submit your next manuscript to BioMed Central and we will help you at every step:}

- We accept pre-submission inquiries

- Our selector tool helps you to find the most relevant journal

- We provide round the clock customer support

- Convenient online submission

- Thorough peer review

- Inclusion in PubMed and all major indexing services

- Maximum visibility for your research

Submit your manuscript at www biomedcentral.com/submit

\section{() Biomed Central}

